\title{
Treatment of stress urinary incontinence with a mobile app
}

\author{
Beuy Joob ${ }^{1} \cdot$ Viroj Wiwanitkit ${ }^{2,3,4}$ \\ Received: 15 January 2018 / Accepted: 12 February 2018 / Published online: 6 March 2018 \\ (C) The International Urogynecological Association 2018
}

Dear Editor, we read the publication on "treatment of stress urinary incontinence with a mobile app" with a great interest [1]. Nyström et al. concluded that "app-based treatment effects are better in women who are interested in and have high expectations of such treatment" [1]. We would like to share our thoughts on this issue. There is no doubt that mobile phone apps may be useful in the clinical management of several diseases. The apps can be a data resource, self-assessment tool or communication portal to a healthcare provider or support group [2]. As a treatment application, the modification of behaviors after obtaining knowledge from a mobile phone app may be possible. However, there are several factors that determine the success. The educational background of the user in their understanding of the content is very important. In Indochina, the average person usually has a low level of education and they may have difficulty understanding and following complex instructions as they appear on many mobile phone apps. In addition, the access to a mobile network is another important factor. In addition, in many regions of the world, remote areas have limited network access, rendering the mobile phone app less useful. So, although we are encouraged by the progress being made in the realm of mobile apps for aid in managing incontinence, it must be remembered that many regions of the world either do not have access or the appropriate educational background to enjoy the benefits of these apps.

\section{Compliance with ethical standards}

Conflicts of interest None.

\section{References}

1. Nyström E, Asklund I, Sjöström M, Stenlund H, Samuelsson E. Treatment of stress urinary incontinence with a mobile app: factors associated with success. Int Urogynecol J. 2017. https://doi.org/10. 1007/s00192-017-3514-1.

2. Schnall R, Iribarren SJ. Review and analysis of existing mobile phone applications for health care-associated infection prevention. Am J Infect Control. 2015;43(6):572-6.
Beuy Joob

beuyjoob@hotmail.com

Sanitation 1, Medical Academic Center, Bangkok, Thailand

2 D Y Patil University, Navi Mumbai, India

3 Joseph Ayo Babalola University, Ilara-Mokin, Nigeria

4 Faculty of Medicine, University of Nis, Nis, Serbia 